\title{
Auszug aus einem Briefe des Herrn Thomas Clausen an den Herausgeber.
}

\author{
Altona 1824. Juni 18.
}

Bei der Berechnung des in Nr. 57 der Astr. Nachrichten abgedruckten Resulțate der Mondssternebeobacintungen habe ich die Anzeige eines Druckfehlers in den Pariser Beobachtungen, Nr. 34. p. 168 ïbersehen. Durch die Verbesserung desselben werden folgende Resultate geändert, die ich folgendermaisen zu berichtigen bitte.

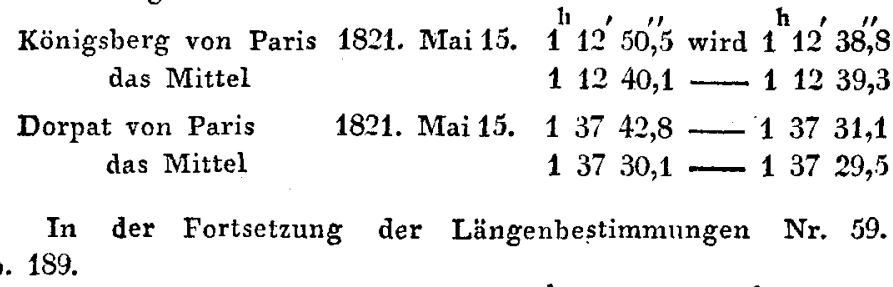

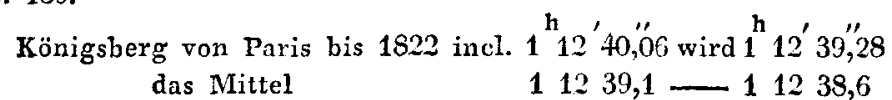

Zugleich nehme ich mir die Freiheit, anf folgende Beob. achtungen aufmerksam zu machen, die fehlerhaft zi seyn scheinen.

Bd. I. p. 170. März 7. X. 212. vermuthlich von 55 leon. statt rom Monde abgezogen.

Bd.II. p. 69. Febr.9. 115 Ariet. statt 33",32 vielleicht 3",32.

p.71. Mai 15. 142 Libr. die Pariser Beobachtung ist abweichend von den in Königsberg und Dorpat angestellten, die unter sich stimmen.

p. 269. Febr.12. VI 43. statt $40^{\prime \prime}, 61$ vermuthlich $35^{\prime \prime}, 61$.

Druckfehler in Nr. 57 .

p. 140. 1. 13. v. o. statt $7^{\prime} 1^{\prime \prime}, 9-7 \cdot 1^{\prime \prime}, 0$.
1. 29. v. o. - März $14-$ März 4.
p. 141. 1. 23. v. u. $-236-336$.
Thomas Clausen.

Auszug aus cinem Briefe des Herrn Ingenicur-Lientenants $v$. Nehus an den Herausgeber. Segeberg 1824. Juni 10.

Am 8ten Juni sah ich bei Fredriksgabe ( 3 Meilen nördlich von Altona) $\frac{T}{2}$ Stunde vor Untergang der Sonne einer hellen Strahl an selbiger, der wohl eine Hohe von 20 bis $30^{\circ}$ erreichte, und dessen Richtung, wie es mir schien, gegen das Zenith ging. Er wurde mitunter plötzlich heller, und schols dann auch weiter in die Höhe, ganz wie das Nordlicht, dem er, in der Art der Bewegung, röllig glich. Die Breite desselben war anscheinend, wie die der untergehenden. Sonnenscheibe. So lange diese über dem Horizonte war, sah er weis aus, wie das Nordlicht,-aber glühender u. blendender; nachher wurde er röthlich, so wie häufig die Dünste des Abendhimmels ins Röthliche spielen. Ich sah $\mathrm{jhn}$ noch eine Stunde nach Sonnenuntergàng, Am stärksten war er immer in der Höhe von circa $10^{\circ}$, weil dort die Atmosphäre am durchsichtigsten wurde; niedriger verlor er sich in den Dünsten, und nach oben wurde er allmählig schwächer und verschwand im Blauen. Die Seiten waren nicht scharf, wie etwa bei Sonnenstrahlen, die durch Wolken fallen, sondern verwaschen, aber ungleich härter als nach oben. Ebenfalls divergirte er nicht, wie diese, sondern schien nach oben zu etwas dünner zu werden, was aber wohl nur der abnehmenden Lichtstärke zuzuschreiben war.

$N e h u s$.

\section{Aus einem Schreiben des Herrn Heineking an den Heransgeber. Altona 1824. Juli 25.}

$D_{i e}$ in Nr. 62. von dem Herrn v. Biela bei Prag bemerkte Lufterscheinung am 8ten Jun. war auch bei uns sichtbar, nur mit dem Unterschiede, dals selbige sich kegelförmig und mit weissem Lichte zeigte. Dieser Lichtkegel stand senkrecht auf der Sonne kurz vor ihrem Untergange, war über $\xi^{\circ}$ lang, hatte unten die Breite der Sonne, und rückte nach jhrem Untergange mit derselben weiter nach Norden fort. Ich sah dieses Phänomen bis beinahe eine Stunde nach Sonnenuntergang, und wurde dann verhindert es weiter zu beachten. Die Grörse desselben nahm nach und nach ab; es ist aber wahrscheinlich noch über eine halbe Stunde sichtbar gewesen. Der Himmel war sehr heiter, nach Sonnenuntergang gänzlich ohne Wolken, und heller Mondschein. Die Sonne war bei ihrem Untergange ein wenig röthlich, und nach $12 \mathrm{Uhr}$ entstand plötzlich ein starker Nebel.

\section{Heineking:}

\section{Auszug aus einem Schreiben des Herrn v. Biela an den Herausgeber. (Beschlufs.)}

Ich habe mehrmals mehrere kleine schwarze Sonnenflecke hart am Rande sehr heller Adern und zwischen denselben entstehen sehen, auch sah ich schon (z. B. am 28sten April d. J.) schwarze Sonnenflecken vor męinen Augen kleiner und matter werden und verschwinden, wornach sich anch die hellen Adern verloren. Ich habe auch die Bemerkung gemacht, dafo kleine Sonnen- flecke sehr leicht mit einem Fernrohr, welches nicht die ganze Sonnenscheibe auf einmal zeigt, zu übersehen und zu verljeren sind, denn ich habe oft zu Viertelstunden mit der Auffindung solcher kleinen Flecken zugebracht, deren Daseyn und beiläufige Stelle mir bekannt waren. Die höhere der zwei Schichten von leuchtenden Wolken, welche Herrschel in der Sonne annimmt, 